\title{
Installation Technique of Fiber Optic Sensor into FRP Used as NSM Structural Strengthening System
}

\author{
Soo-Yeon Seo ${ }^{1, * \mathbb{C}}$, Jeong-Hun Park ${ }^{1}$, Hyun-Do Yun ${ }^{2}$ (D) and Kang-Su Kim ${ }^{3}$ (D) \\ 1 Department of Architectural Engineering, Korea National University of Transportation, Chungju 27389, \\ Korea; pjh4198@ut.ac.kr \\ 2 Department of Architectural Engineering, Chungnam National University, Daejeon 34143, Korea; \\ wiseroad@cnu.ac.kr \\ 3 Department of Architectural Engineering, University of Seoul, Seoul 02054, Korea; kangkim@uos.ac.kr \\ * Correspondence: syseo@ut.ac.kr
}

Received: 6 September 2020; Accepted: 13 October 2020; Published: 15 October 2020

check for updates

\begin{abstract}
Recently, it has become necessary to develop a monitoring technology that combines an FBG (fiber Bragg grating) sensor as a means for continuously monitoring whether the reinforcing effect of an FRP (fiber-reinforced polymer) is maintained on FRP-reinforced structural members. However, most existing research focuses on the insertion of FBG sensors into bar-shaped FRPs, and there is a lack of studies that analyze the details for an FRP strip combined with FBG sensors. In this regard, this paper seeks to develop a reinforcement for an NSM (near-surface-mounted) retrofit in which an optical fiber with an FBG sensor is combined with FRP strips. For this, a series of experiments were performed to find the adhesive strength of optical fiber-epoxy-FRP interfaces, the tensile strength of the FBG sensor part of optical fiber with a reflection lattice, and the sensing performance depending on the adhesion length between the optical fiber and the FRP strips. As a result of the study, the adhesion length not less than $20 \mathrm{~mm}$ in one direction from the center, with a total adhesion length of $40 \mathrm{~mm}$, needs to be secured when the optical fiber with an FBG is attached and fixed between the two FRP strips with epoxy. In addition, it is expected that the proposed model can be used to properly predict the strain transfer of an FRP strip with a fiber optic sensor and can also be utilized when determining optimum dimensions.
\end{abstract}

Keywords: fiber Bragg grating sensor; FRP strip; NSM retrofit; adhesion length; sensing performance

\section{Introduction}

Buildings undergo changes in structural functions due to the passage of time and environmental factors. Thus, they suffer problems in terms of structural safety. In response, various methods for monitoring the structural behavior of buildings have been developed and applied to actual structures. Recently, structural health monitoring (SHM) technologies have been applied to structures larger than a certain size to monitor the structural characteristics from the construction stage to the use stage. The aim of SHM is to monitor the behavior of structures, detect damage, estimate the current health status of the structure, and even predict future failure during use [1-3]. The optical fiber (OF) sensor is one of the most widely used measurement sensors for SHM. Since the introduction of measuring technologies using OF sensors by Hill [4], related studies have been actively conducted, and the technologies are now being used in monitoring the health status of various structures. Compared to the conventional electrical resistance measurement method, the OF sensor is capable of long-term measurement and boasts excellent corrosion resistance, and it is not subject to electromagnetic influences, resulting in no noise in the measured value. In addition, while the electrical resistance measurement method cannot perform multiple measurements on one line, the measuring technology using an optical fiber enables 
multiple measurements and networking, which makes it possible to identify the overall behavior of the target structural member [5-7]. The use of fiber Bragg grating (FBG)-based fiber optic sensing has already been shown to be reliable and stable with time to observe structural behavior [8]. Accordingly, the FBG-based OF sensor has been widely applied as a non-destructive evaluation technology to measure the deformation and temperature history of structural members [9].

In recent years, a reinforcement method using fiber-reinforced polymers (FRPs) has been extensively applied to reinforced concrete structures, and thus ways to constantly monitor the persistence of the FRP reinforcement effect have been required. In this regard, if the FBG sensor is properly coupled to the FRP reinforcement and used for real-time monitoring, the reinforcement effect can be checked at all times, thus ensuring the efficient maintenance of the structural member after reinforcement [10-15]. The application of the FBG sensor to the FRP has been mostly used to monitor the stress losses of the FRP in Reinforced Concrete (RC) beams using prestressed FRP plates $[16,17]$. In addition, a technology that combines the FBG sensor with the sheet or bar type of reinforcement materials has been developed to continuously monitor the reinforcing effect of the FRP used in strengthening reinforced concrete members [18-20].

Epoxy resins are mainly used to couple the FBG sensor to the FRP. The main variables that can affect the sensing performance of the FBG sensor embedded into the FRP include the thickness of the adhesive and the elastic modulus of the coating material surrounding the FBG sensor. It is known that when the thickness of the adhesive increases, the strain of the FBG sensor is relatively smaller than that of the host material [11]. This suggests that there may be a difference in the sensing capacity depending on the method in which the FBG sensor is attached to the FRP.

Recently, the application of the FRP reinforcement has been increased to improve the structural capacity of reinforced concrete structures. There are two types of strengthening techniques using the FRP for reinforced concrete structures: externally bonded (EB) reinforcement and near-surface-mounted (NSM) retrofit, as shown in Figure 1. In the NSM technique, the method of embedding the FRP in the form of bars or plates is mainly used, and although the process of forming grooves on the surface is added in this method, it ensures excellent reinforcing effects. A series of studies have recently demonstrated the excellence of the NSM technique using strip-type FRPs [21-25]. However, it is necessary to continuously monitor whether or not the reinforcing effect of the FRP is maintained in the structural members reinforced with FRPs. For this, it is necessary to develop a monitoring technology that combines an FBG sensor. However, there is a lack of research on the details of the NSM FRP strips combined with an FBG sensor.

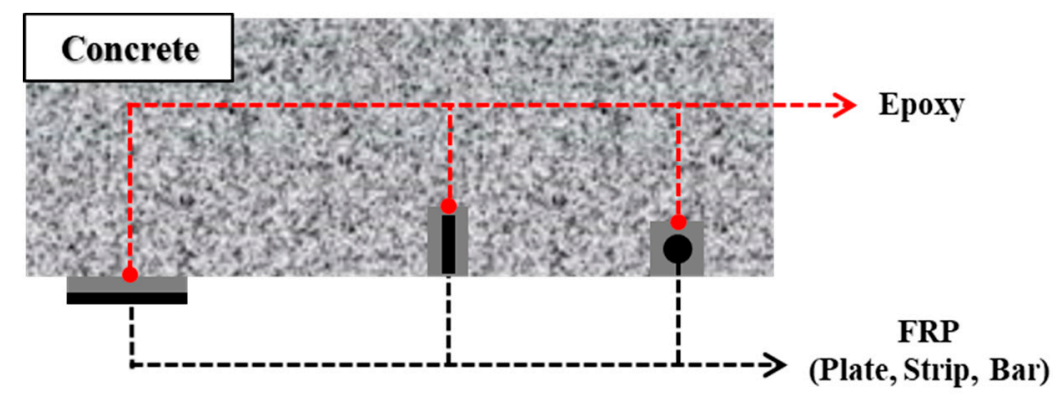

(a)

(b)

Figure 1. Structural reinforcing methods by using a fiber-reinforced polymer (FRP) for concrete: (a) EBR (externally bonded retrofit); (b) NSMR (near-surface-mounted retrofit).

This study aimed to develop a strip-type FRP reinforcement in which FBG sensors are embedded for monitoring of the FRP after a retrofit. In particular, it sought to investigate the combining method of the FRP and FBG sensor. To this end, a series of experiments were conducted to identify the tensile strength of the OF in which the FBG is formed and then examine the adhesive strength when attaching the OF to the FRP using epoxy. In addition, an analysis model was applied to evaluate the sensing 
capacity according to the adhesion length when the FBG sensor was coupled to the FRP with epoxy and was then evaluated experimentally.

\section{FRP Strip Reinforcement with Optical Fiber Sensor}

When strengthening concrete structures with the FRP, it attached to the surface of the member or embedded inside the groove as shown in Figure 1. Typical OFs consist of the core, cladding, coating, and jacket as shown in Figure 2. The core and cladding constitute a core part. The role of the jacket is to prevent the damage due to an impact or brittle failure. In the OF sensor, the FBG is formed in the core part and coated, and then the coated part is directly attached to the host material and fixed. The FBG sensor is attached to the outside of the host material, FRP, as shown in Figure 3. When the FRP strip fabricated in this way is used for an NSM retrofit, the FRP inside the concrete groove is bonded to the concrete with epoxy as shown in Figure 4. In this case, as the OF is exposed to the shear stress that exists between the FRP and concrete, it is highly likely to be damaged. To address this problem, this study proposed the details to fix the optical fiber with epoxy while maintaining an appropriate thickness between the two FRP plates as shown in Figure 5.

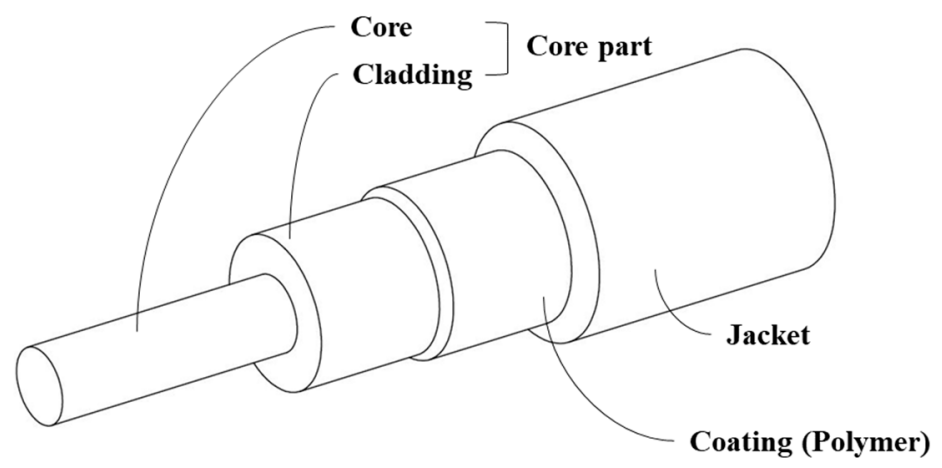

Figure 2. Configuration of optical fiber.

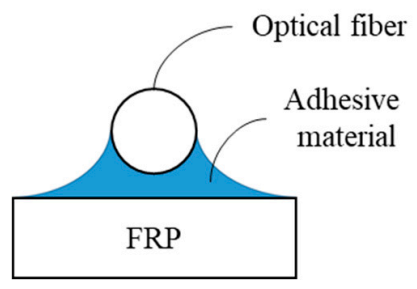

(a)

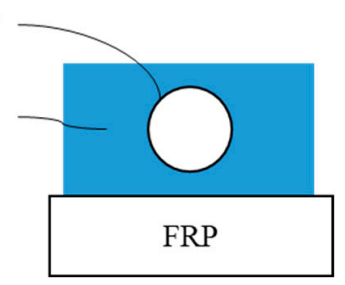

(b)

Figure 3. Bonding concept of an FBG to the surface of an FRP strip: (a) Surface bonding by epoxy resin; (b) Wrapping an FBG with epoxy resin.

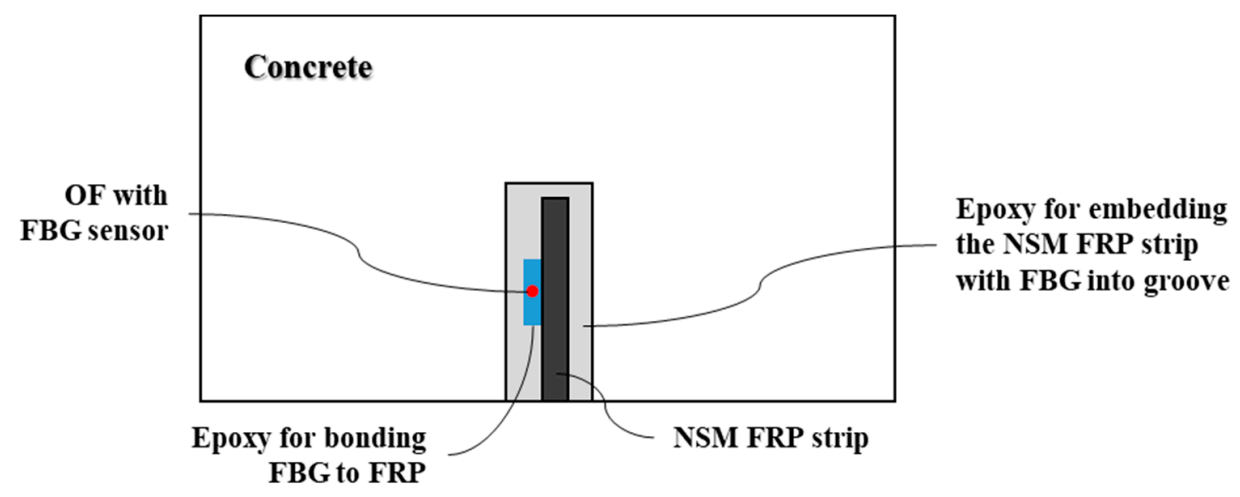

Figure 4. Embedding the FRP strip with externally bonded FBG into the groove of the concrete member. OF: optical fiber; FBG: fiber Bragg grating; NSM: near-surface-mounted. 


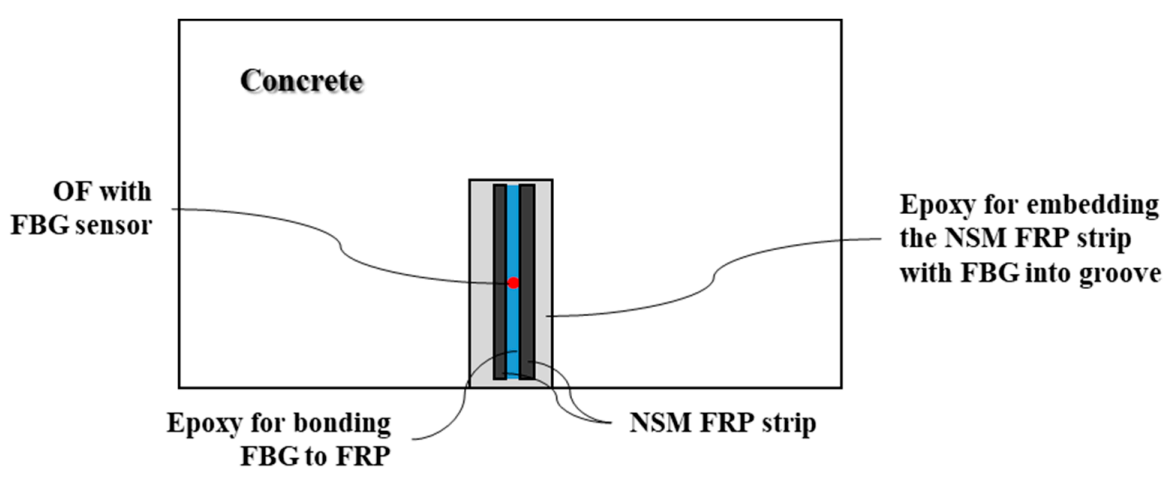

Figure 5. Proposed FRP strip with an embedded FBG for an NSM retrofit and monitoring.

\section{Tensile Test of Optical Fiber Inserted between FRP Strips}

In order to (1) determine the minimum adhesion length for the OF fixed between the two FRP strips to exert sufficient strength, and to (2) investigate whether the FBG sensor can sufficiently display the strain information that occurs in the FRP, a tensile test was conducted using the adhesion length of the OF between the FRPs as a variable. In the actual concrete member strengthened with the NSM FRP, the tensile stress in the longitudinal direction of the FRP governs. The optical fiber embedded between the FRPs is subjected to the tensile stress almost like the FRP, thus a test for the tensile stress was conducted.

\subsection{Plan of Tensile Test}

To accurately identify the tensile strength of the OF used in this study, a tensile test was conducted after fixing both ends of the OF between the two Carbon FRP (CFRP) strips as shown in Figure 6. In the fabrication process of specimens, the adhesion length was set to 10,30,50, and $100 \mathrm{~mm}$, respectively, in order to determine the minimum adhesion length for the $\mathrm{OF}$ to exert sufficient tensile strength when using epoxy as the bonding material. These were based on the results of related studies $[26,27]$ and the adhesion strength of epoxy. Meanwhile, when the FBG is formed in the OF with a laser, the tensile strength decreases due to the cross-sectional loss of the OF. Therefore, a specimen designed to identify the tensile strength of the OF in which a grating is formed was fabricated as well. Table 1 shows a list of tensile specimens, and three samples were produced for each specimen. In the fabrication of tensile specimens, two FRP strips with a width of $16 \mathrm{~mm}$ and a thickness of $1.2 \mathrm{~mm}$ were fixed at both ends of the OF while maintaining a thickness of $2.6 \mathrm{~mm}$ of epoxy resin. Figure 7 shows the ends of the fabricated specimen. Epoxy may be affected by temperature during curing [28]. However, the epoxy used in this study was cured for two days in the range of $22 \pm 2{ }^{\circ} \mathrm{C}$, as suggested by the manufacturer. The experiment was conducted under $22 \pm 2{ }^{\circ} \mathrm{C}$ which is a temperature condition where the adhesive strength of the epoxy could be sufficiently achieved. The Japan Shimadzu's UTM (AG-250) with a capacity of $250 \mathrm{kN}$ was used in the tensile test. The tensile force was gradually increased with a loading speed of $3.6 \mathrm{~mm} / \mathrm{min}$ until the specimen underwent failure after $50 \mathrm{~mm}$ of the FRP portions at both ends of the specimen were held tightly by plate-type grips with a lightly serrated surface as shown in Figure 8. The material properties of the OF, FRP, and epoxy used are summarized in Tables 2-4, respectively. These data are all provided by the manufacturer.

Table 1. Specimen list for the tensile test of the OF.

\begin{tabular}{ccc}
\hline Specimen Name & Bond Length $(\mathbf{m m})$ & FBG \\
\hline OF-10 & 10 & \\
OF-30 & 30 & None \\
OF-50 & 50 & \\
OF-100 & 100 & FBG \\
OF-100-B & & \\
\hline
\end{tabular}




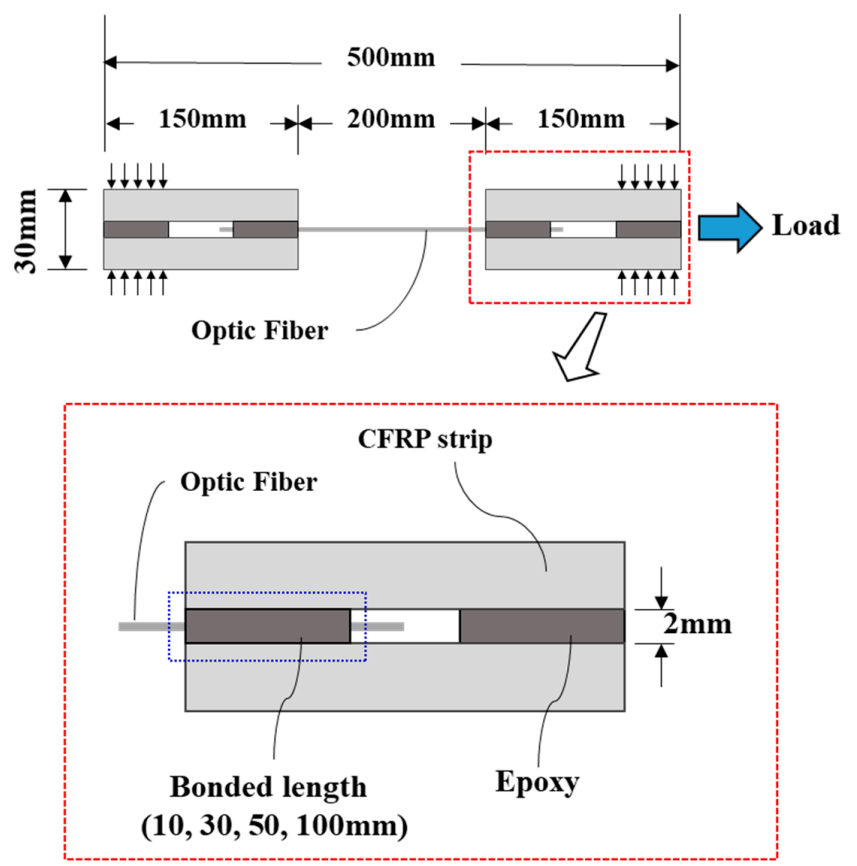

Figure 6. Detail of OF specimens for the tensile test.

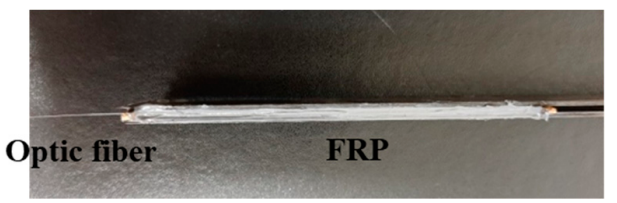

Figure 7. Configuration of the optical fiber.



Figure 8. Set up for the tensile test of the OF. 
Table 2. Dimension and tensile strength of the optic fiber.

\begin{tabular}{|c|c|c|c|}
\hline Type & Diameter of Core $(\mathrm{mm})$ & Diameter (mm) & Tensile Strength $\left(\mathrm{N} / \mathrm{mm}^{2}\right)$ \\
\hline ITU-T G.657.B3 & 0.125 & 0.250 & 690 \\
\hline
\end{tabular}

Table 3. Dimension and mechanical properties of the FRP strip.

\begin{tabular}{|c|c|c|c|c|}
\hline Type & $\begin{array}{l}\text { Thickness } \\
\text { (mm) }\end{array}$ & $\begin{array}{l}\text { Width } \\
\text { (mm) }\end{array}$ & $\begin{array}{l}\text { Tensile Strength } \\
\left(\mathrm{N} / \mathrm{mm}^{2}\right)\end{array}$ & $\begin{array}{l}\text { Elastic Module } \\
\left(\mathrm{N} / \mathrm{mm}^{2}\right)\end{array}$ \\
\hline SK-CPS 0512 & 1.2 & 50 & 2942 & 165,000 \\
\hline
\end{tabular}

Table 4. Mechanical properties of epoxy.

\begin{tabular}{|c|c|c|c|}
\hline Type & $\begin{array}{l}\text { Compressive Strength } \\
\left(\mathrm{N} / \mathrm{mm}^{2}\right)\end{array}$ & $\begin{array}{l}\text { Shear Bond Strength } \\
\left(\mathrm{N} / \mathrm{mm}^{2}\right)\end{array}$ & $\begin{array}{l}\text { Bond Strength to } \\
\text { Concrete }\left(\mathrm{N} / \mathrm{mm}^{2}\right)\end{array}$ \\
\hline SK-CPA10 & 90 & 10 & 1.5 \\
\hline
\end{tabular}

\subsection{Tensile Strength of Optical Fiber Inserted between FRP Strips}

From the test, the tensile strength of the specimens decreased rapidly after the concentration of failure at the coating part regardless of adhesion lengths as shown in Figure 9. SEM photographs of the fractured OF in each specimen were performed using Japan JEOL's JSM-7610. Figure 10 shows the SEM image. The unit length indicated by the white bar at the bottom of each figure is $100 \mu \mathrm{m}$. The images show (a) the OF before tensile stress is applied, (b) the slip that occurs between the core and coating after the failure of the coating part, and (c) tensile fracture. The tensile strengths according to the adhesion length are summarized in Table 5. The third test specimen of OF-100 was fractured early and the test result was excluded from the analysis. The tensile strength is obtained by dividing the load by the cross-sectional area including the coating. Although the deviation of the values between the specimens with the same adhesion length is large, the maximum tensile strength tends to increase in proportion to the attachment length. Figure 11 shows the minimum and maximum values of three specimens for each adhesion length. There was no difference in strength, even when the adhesion length was increased from $10 \mathrm{~mm}$ to $30 \mathrm{~mm}$. However, at longer adhesion lengths than $30 \mathrm{~mm}$, the maximum strength increased in proportion to the adhesion length. When the adhesion length was $100 \mathrm{~mm}$, the maximum strength was reached as the tensile fracture occurred in the OF. At this time, the tensile strength obtained by dividing the load by the cross-sectional area including coating was $237 \mathrm{MPa}$ on average, while the tensile strength divided by the cross-sectional area of the core excluding the coating was $950 \mathrm{MPa}$ on average. When the FBG was formed, the strength was $21.6 \%$ lower than that of the case without an FBG. When the adhesion length between the FRP and OF is not less than $30 \mathrm{~mm}$, the interface can have a higher bond strength than the tensile strength of the OF with an FBG. In the OF-100-B specimen, the strain of the OF was measured from the FBG on an optical fiber. Figure 12 shows the strain-stress curve of the specimen in which the FBG was formed. The stress on the vertical axis is the value obtained by dividing the applied load by the cross-sectional area of the core part, while the horizontal axis represents the strain measured from the FBG sensor. The process of converting the value measured from the FBG sensor to the strain is described in Section 3.2. The stress-strain relationship is linear, and the tensile fracture occurs immediately after the maximum strength. In the curve of Figure 12, the stiffness obtained by dividing the stress by the strain ranged from 18,982 to $19,335 \mathrm{MPa}$, showing an average of 19,146 MPa. 


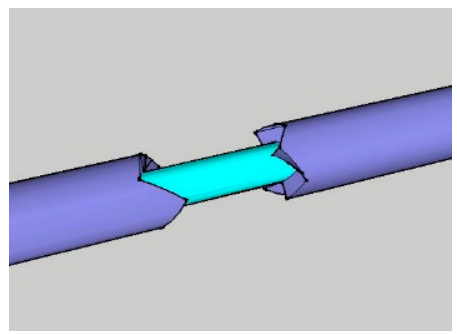

(a)

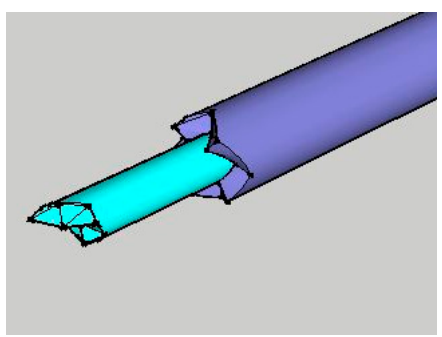

(b)

Figure 9. Failure pattern of the OF: (a) Slip between the core and coating after the failure of coating; (b) Tension failure of the core.
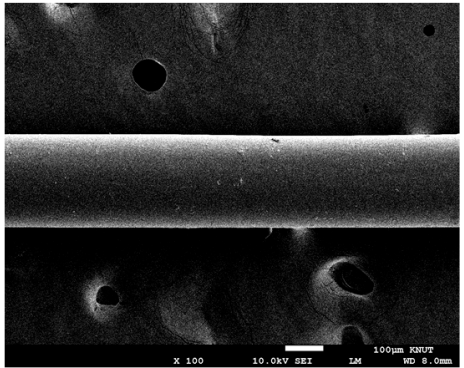

(a)

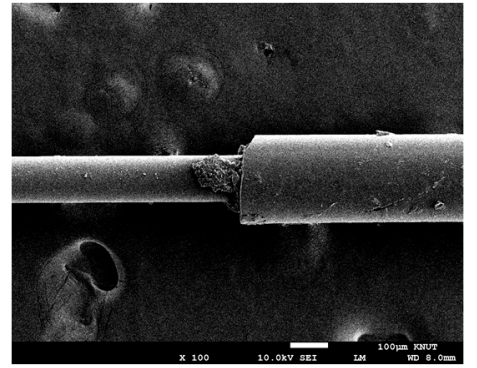

(b)

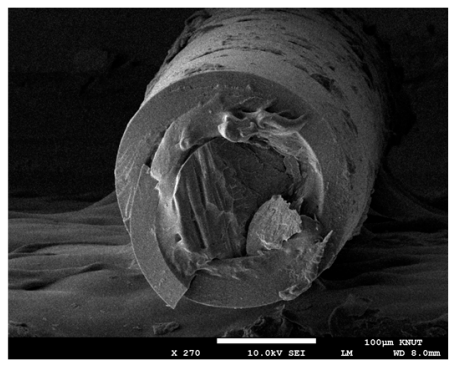

(c)

Figure 10. Failed image of the OF: (a) Before acting tensile stress $(\times 100)$; (b) Occurrence of slippage between the core and coating $(\times 100)$; (c) Fractured section of the $\mathrm{OF}(\times 270)$.

Table 5. Result of the tension test.

\begin{tabular}{ccccccc}
\hline \multirow{2}{*}{$\begin{array}{c}\text { Specimen } \\
\text { Name }\end{array}$} & Classification & \multicolumn{3}{c}{ Number } & Average & $\begin{array}{c}\text { COV } \\
\text { (\%) }\end{array}$ \\
\cline { 3 - 5 } & & $\mathbf{1}$ & $\mathbf{2}$ & $\mathbf{3}$ & & \\
\hline OF-10 & Strength $\left(\mathrm{N} / \mathrm{mm}^{2}\right)$ & 229.52 & 206.24 & 175.65 & 203.80 & 13.26 \\
OF-30 & Strength $\left(\mathrm{N} / \mathrm{mm}^{2}\right)$ & 184.78 & 209.87 & 204.10 & 199.58 & 6.58 \\
OF-50 & Strength $\left(\mathrm{N} / \mathrm{mm}^{2}\right)$ & 229.78 & 224.47 & 216.86 & 223.70 & 2.9 \\
OF-100 & Strength $\left(\mathrm{N} / \mathrm{mm}^{2}\right)$ & 272.15 & 260.30 & $180.41+$ & 266.23 & 3.14 \\
& Strength $\left(\mathrm{N} / \mathrm{mm}^{2}\right)$ & 181.23 & 163.57 & 214.11 & 186.30 & 13.77 \\
OF-100-B & Stiffness * $\left(\mathrm{kN} / \mathrm{mm}^{2}\right)$ & 19,335 & 19,121 & 18,982 & 19,052 & 0.52 \\
\hline
\end{tabular}

\# Coefficient of variable. ${ }^{+}$This data was excluded from analysis as a result of premature failure. ${ }^{*}$ Stiffness is obtained by dividing the stress by the strain at peak.

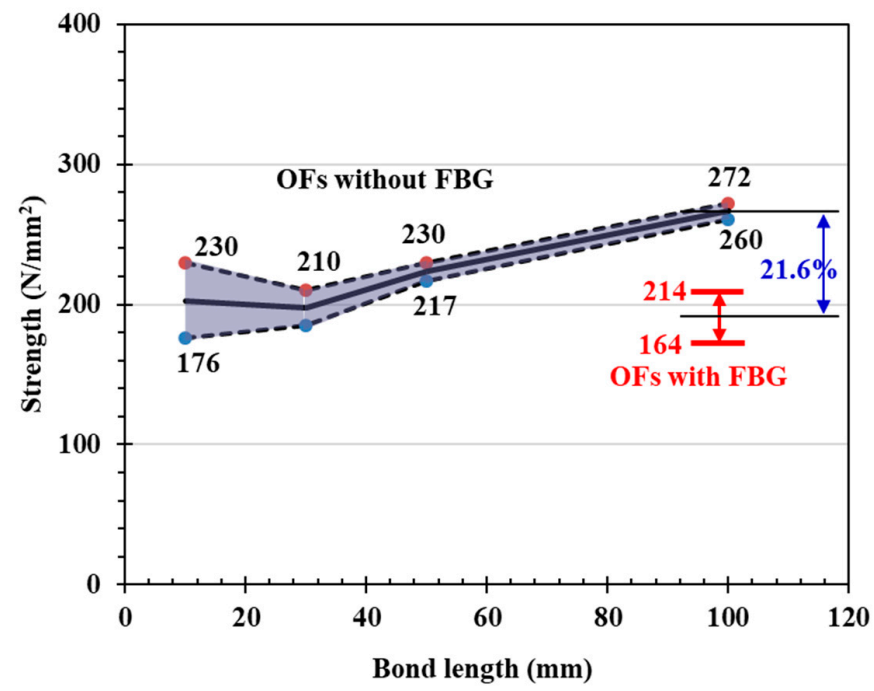

Figure 11. Variation of the ultimate strength of the OFs corresponding to bond length. 


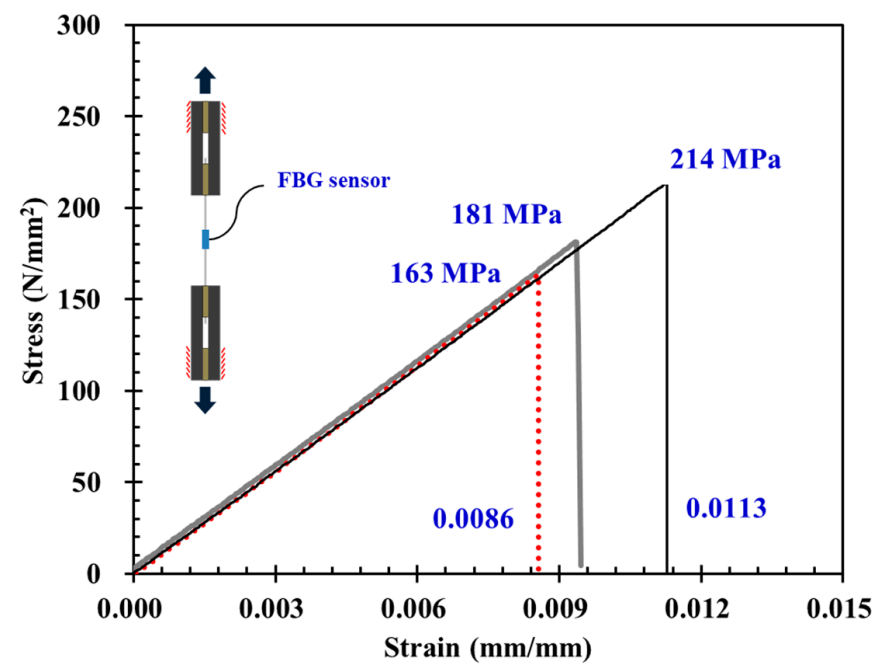

Figure 12. Stress-strain curves of the OF with an FBG.

\subsection{Sensing Capacity of Optical Fiber Inserted between FRP Strips}

As stated above, the strain generated in the FRP may not be appropriately transferred to the OF sensor according to the shear lag phenomenon that occurs between the core part and coating as well as between coating and epoxy. This is closely related to the adhesion length of the OF. Accordingly, an experiment was conducted to observe the sensing performance according to the change in the adhesion length of the OF. Table 6 shows a list of specimens for evaluating the sensing performance of the OF embedded into FRP strips with epoxy. The shape of the FRP strip with the OF is as shown in Figure 5. It was made by integrating with epoxy resin after placing the OF with an FBG between the two FRP strips. Figure 13 represents the FRP strip. The adhesion length " $L$ " of the OF was changed to 10, 20, 30, 40 , and $50 \mathrm{~mm}$, and the electric strain gauge was attached at the center of each specimen length. The sensing performance was evaluated by comparing the result obtained from the strain gauge and the sensing result of the OF. Regarding the production of the FRP strip with the OF, the epoxy thickness between the two FRP strips was $2.6 \mathrm{~mm}$ in consideration of the outer diameter of the tube. FRP pieces were installed with a cyanoacrylate $\mathrm{CN}$ bond to maintain an interval between two FRPs. The OF was placed to keep the planned adhesion length at the center of the test specimen, point bonded with a $\mathrm{CN}$ bond, applied with epoxy, and then attached with the upper FRP plate to produce the FRP strip reinforcement with the OF.

Figure 14 shows the tensile test setup. The end portion of the FRP strip was reinforced with an epoxy-filled square steel box with reference to ASTM D3039 [29]. The OF, FRP strip, and epoxy resin are the same as those used in Section 3.2, and the material properties are summarized in Tables 2-4. As loading equipment, the UTM of Korea Daeyeong's DYHU-200TC was used. The tensile force applied to the specimen was a third of the tensile strength of the OF-100-B specimen shown in Table 4, which is the OF with an FBG, and the experiment was carried out by repeating it three times for each specimen with a loading speed of $3.6 \mathrm{~mm} / \mathrm{min}$.

Table 6. Specimen list for the evaluation of the sensing capacity of the FRP strip with a fiber optic sensor.

\begin{tabular}{cc}
\hline Specimen Name & Bond Length, L (mm) \\
\hline FBG-F-10 & 10 \\
FBG-F-20 & 20 \\
FBG-F-30 & 30 \\
FBG-F-40 & 40 \\
FBG-F-50 & 50 \\
\hline
\end{tabular}

Each specimen was tested three times. 

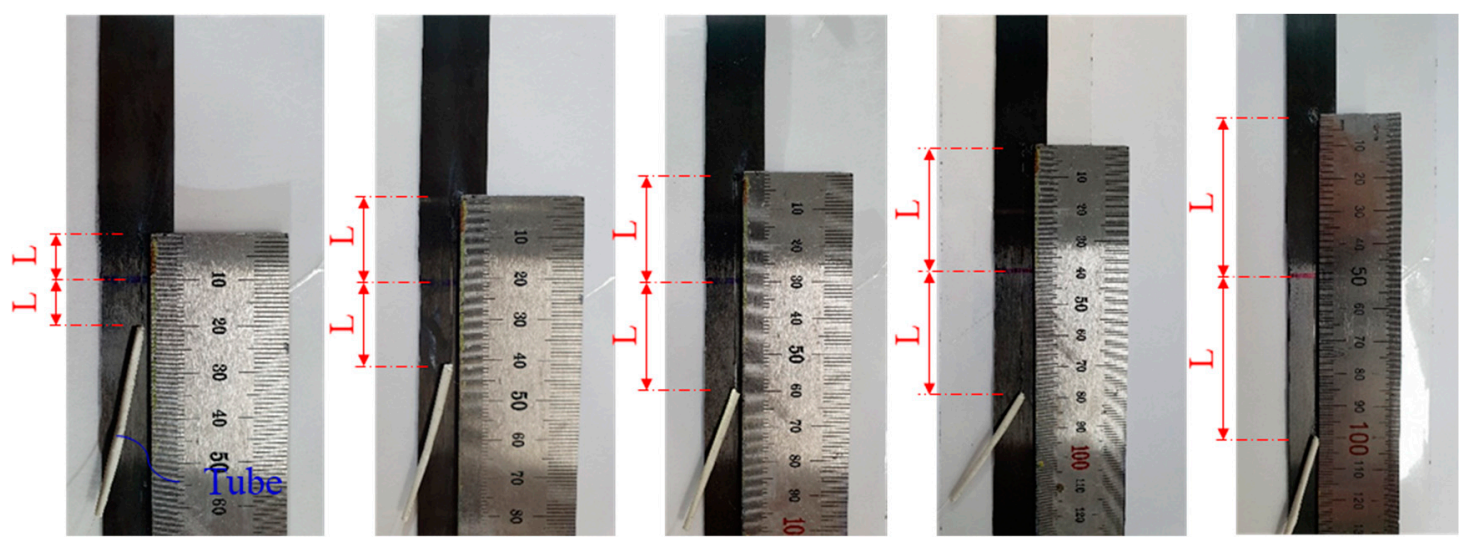

(a)

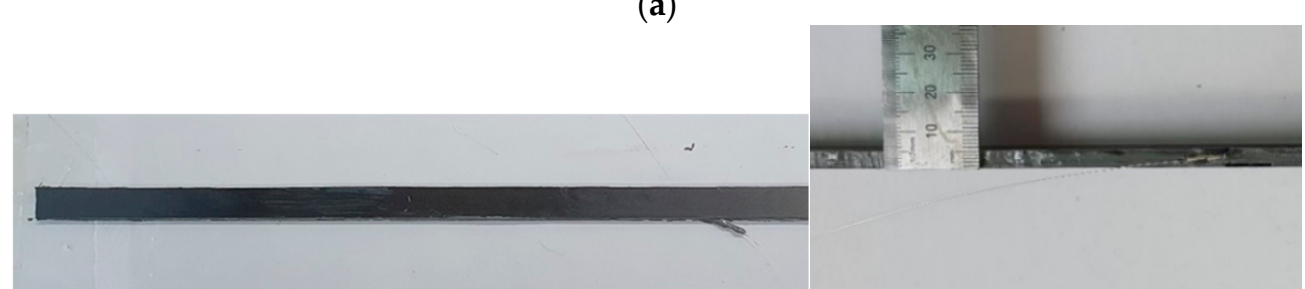

(b)

Figure 13. Fabrication process of the FRP strip reinforcement: (a) Installment of the OF with an FBG on the bottom FRP strip to keep the planned bond length; (b) Perfect bonding of two FRP strips with epoxy.


Figure 14. Test setup for the tensile test of the FRP strip with the OF.

The measurement principle of the OF sensor is to use the characteristic that the wavelength of light reflected from each grating varies depending on changes in external conditions, such as temperature and intensity. As shown in Figure 15, when a wide spectrum is incident, the fiber Bragg grating 
reflects only a specific wavelength and transmits the other wavelengths. In addition, when the ambient temperature of the grating changes or tension is applied to the grating, the reflective index or length of the OF changes, and the specific wavelength reflected also changes. Therefore, temperature, tension, pressure, and bending, etc., can be detected by measuring the wavelength of light reflected from the FBG. When the wide spectrum is incident on the OF, the reflected signal causes interference and is reflected on the OF grating, and the remaining wavelengths pass through and are not involved in the measurement as shown in Equation (1) [30].

$$
\lambda_{B}=2 n \Lambda
$$

where $\lambda_{B}$ is the reflected wavelength $(\mu \mathrm{m}), n$ is the effective reflection index, and $\Lambda$ is the period of the FBG.

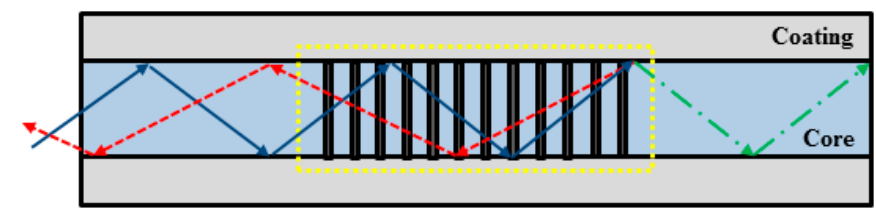

FBG Sensor in Optic Fiber

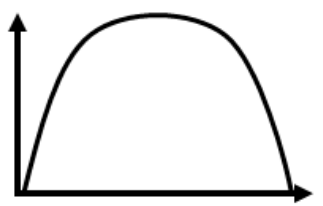

(a)

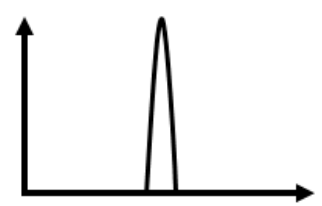

(b)

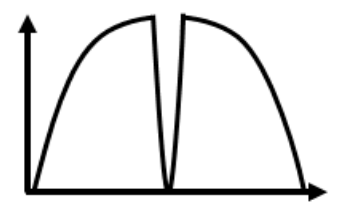

(c)

Figure 15. Reflection of a wave in the OF with an FBG: (a) Input; (b) Reflected; (c) Transmitted.

The Bragg wavelength reflected from the grating is a function of the effective refractive index and the grating period. Since the main meaning of the effective refractive index and the grating is a function of the temperature and strain, the reflected wavelength changes as temperature or deformation are given to the fiber Bragg grating. In the Bragg equation, if the Bragg wavelength is differentiated, and the temperature, strain, effective refractive index, and grating period are then substituted, Equation (2) can be obtained as shown below.

$$
\Delta \lambda_{B}=\lambda_{B}\left[(\alpha+\xi) \Delta T+\left(1-P_{e}\right) \Delta \varepsilon\right]=K_{T} \Delta T+K_{\varepsilon} \Delta \varepsilon
$$

where $\Delta \lambda_{B}$ is the change of the wavelength $(\mu \mathrm{m}), \alpha$ is the expansion coefficient corresponding to temperature, $\xi$ is the coefficient considering the change of reflection corresponding to temperature, $\Delta T$ is temperature change, $P_{e}$ is the photo-elastic coefficient, $\Delta \varepsilon$ is the change of strain in the FBG, and $K_{T}$ and $K_{\varepsilon}$ are coefficients considering the changes of temperature and reflection, respectively.

Therefore, the strain can be calculated from the measured wavelength change information as shown in Equation (3).

$$
\Delta \varepsilon=\frac{\Delta \lambda_{B}-K_{T} \Delta T}{K_{\varepsilon}}=\frac{1}{1-P_{e}}\left[\frac{\Delta \lambda_{B}}{\lambda_{B}}-(\alpha+\xi) \Delta T\right]
$$

The photo-elastic modulus $\left(P_{e}\right)$, reflected wavelength $\left(\lambda_{B}\right)$, expansion coefficient corresponding to temperature $(\alpha)$, and coefficient considering the change of reflection corresponding to temperature $(\xi)$ values of the OF used in this study are summarized in Table 7. The temperature change was not considered in the calculation since the temperature was kept constant in the laboratory.

Equation (3) was used to convert the tensile test results of the FRP strip with an OF according to the adhesion length into strain and compare it with the strain information of the electric gauge as shown in Figure 16. It was found that the strain value of the electric gauge and the strain of the OF 
exhibit a linear relationship for all adhesion lengths. However, when the adhesion length " $\mathrm{L}$ " is $10 \mathrm{~mm}$, the strain of the OF sensor consistently shows a value corresponding to $74 \%$ of the electric gauge strain. This is because the strain that occurred in the FRP is not sufficiently transferred to the OF due to the shear lag effect. On the other hand, when the adhesion length is $20 \mathrm{~mm}$ or more, the strain of the OF sensor is almost identical to that of the electric gauge. These results suggest that an adhesion length of $20 \mathrm{~mm}$ or more in one direction from the center, with a total adhesion length of more than $40 \mathrm{~mm}$, needs to be secured when the OF is attached and fixed between the two FRP strips with epoxy.

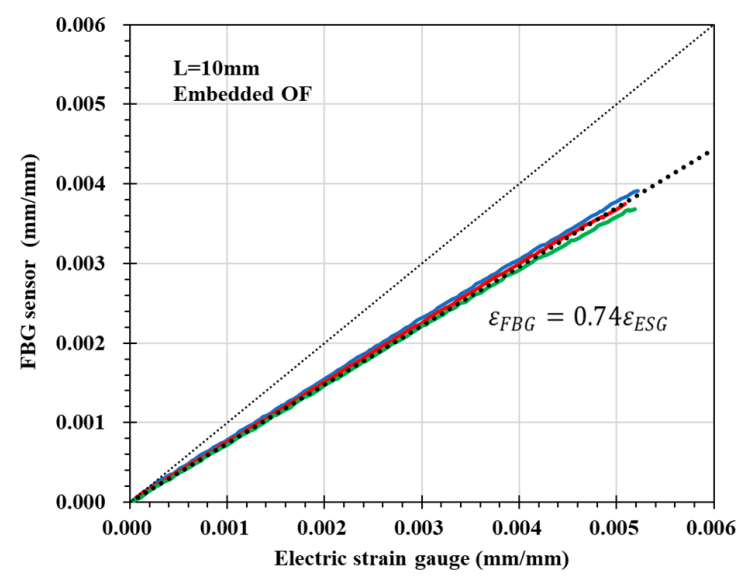

(a)

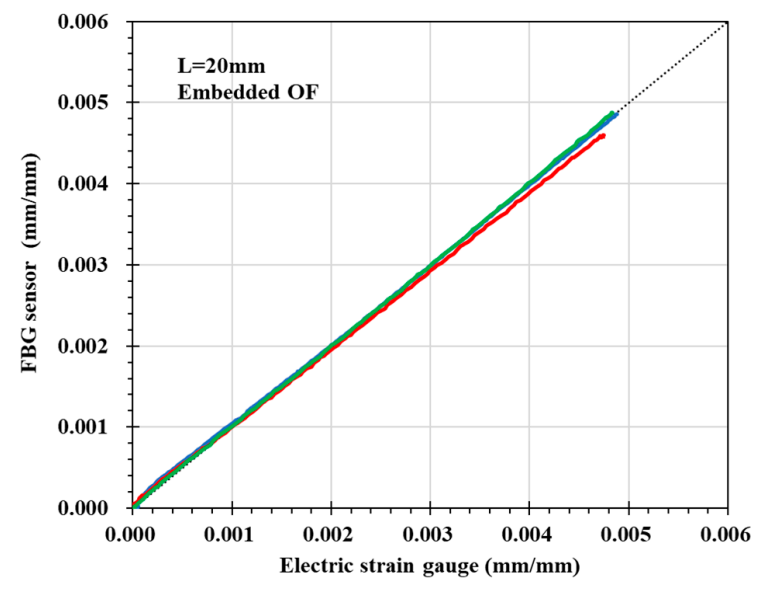

(b)

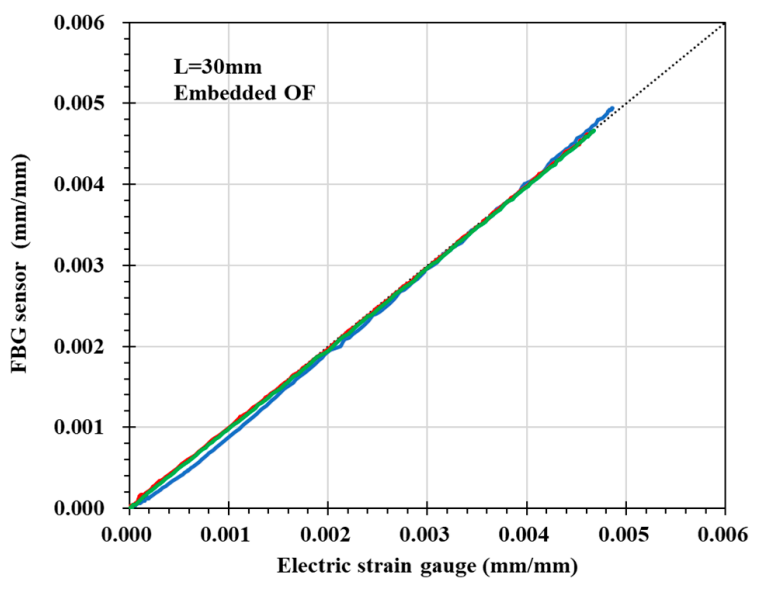

(c)

Figure 16. Cont. 


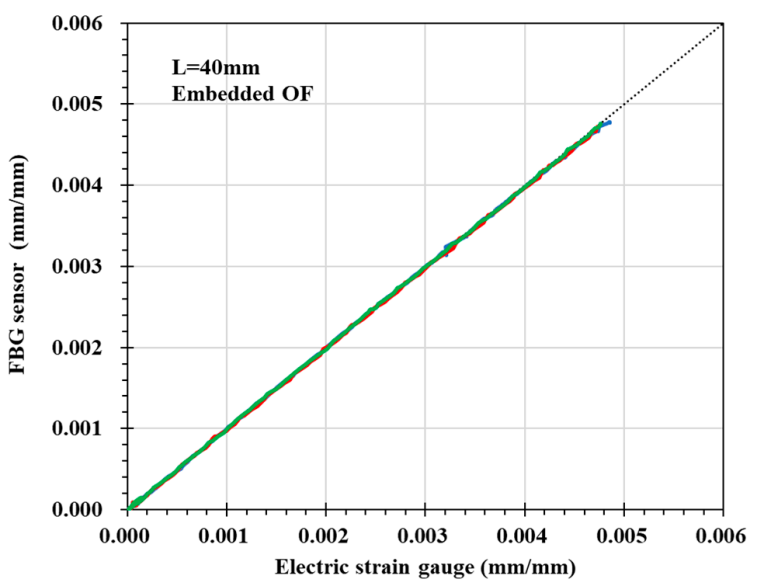

(d)

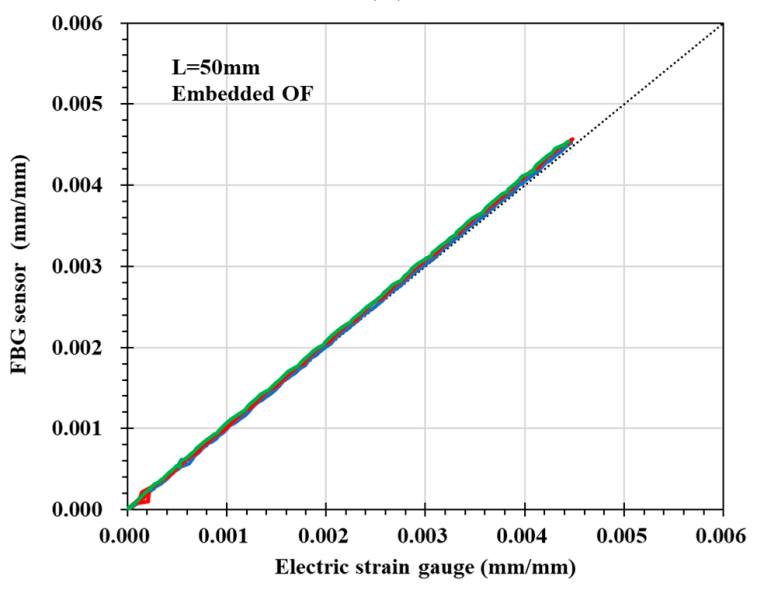

(e)

Figure 16. Comparison of the strain between the FBG sensor and electric gauge: (a) FBG-F-10; (b) FBG-F-20; (c) FBG-F-30; (d) FBG-F-40; (e) FBG-F-50.

Table 7. Optical properties of the OF with an FBG.

\begin{tabular}{ccccc}
\hline Material & $\boldsymbol{P}_{\boldsymbol{e}}$ & $\lambda_{\boldsymbol{B}}(\boldsymbol{\mu \mathrm { m }})$ & $\alpha\left(\times \mathbf{1 0}-\mathbf{6} /{ }^{\circ} \mathrm{C}\right)$ & $\xi\left(\times 10^{-6} /{ }^{\circ} \mathrm{C}\right)$ \\
\hline Silica fiber & $0.22^{*}$ & $1050^{+}$ & $0.55^{*}$ & $8.6^{*}$ \\
\hline
\end{tabular}

* These are the values used in the research by Werneck et al. [30] ${ }^{+}$The value is suggested by the manufacturer.

\section{Strain Transfer Mechanism in the FRP Strip with Fiber Optic Sensor}

The theoretical model of the FRP strip with a fiber optic sensor in which the OF is embedded between two FRP strips is based on the theoretical model of Zhao et al. [26], as shown in Figure 17. When tensile stress occurs in the FRP, the deformation caused by the stress is transferred to the OF through the epoxy, thus leading to changes in the optical signal transfer [31]. The change of the strain transfer in the OF attached to the surface of the FRP can be estimated by the following assumptions [26,27,31-33]. Fiber core, coating, and FRP strips all behave as linear elastic isotropic materials. FRP exhibits homogeneous behavior along the length of the fiber.

(1) FRP strips are subjected to uniform axial stress, while the fiber core, coating, and adhesive layer are not directly subjected to any external loadings.

(2) The interface of all materials is fully bonded, and the displacements maintain consistency along the interface. 

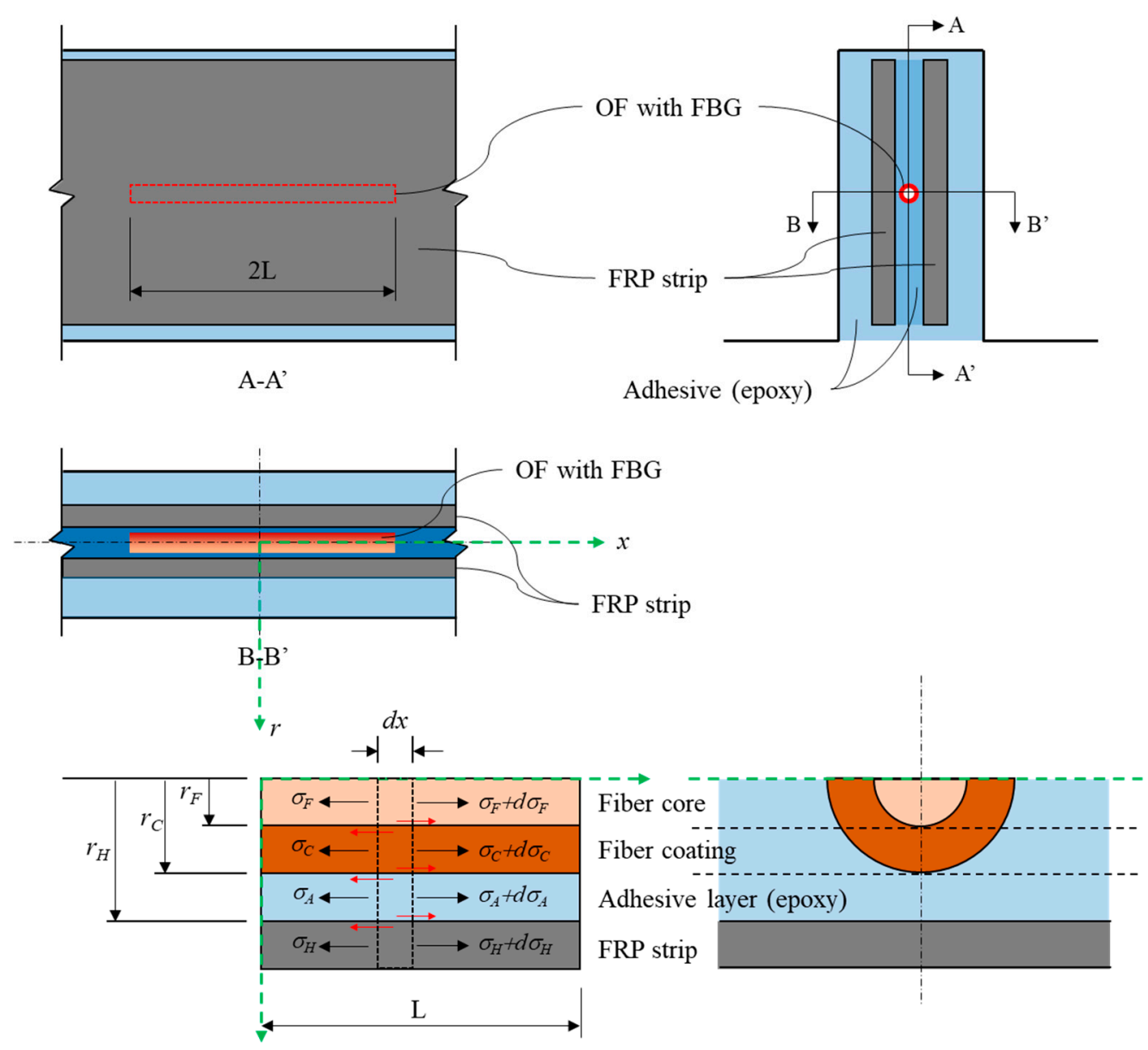

Figure 17. Analytical model of the FRP strip with an embedded OF.

Given the above assumptions and the symmetry in the orthogonal direction, the equilibrium equation for $1 / 2$ of the thickness direction of the infinitesimal fiber core is as follows.

$$
\frac{1}{2} \pi r_{F}^{2}\left(\sigma_{F}+d \sigma_{F}-\sigma_{F}\right)+\pi r_{F} \tau\left(x, r_{F}\right) d x=0
$$

where

$$
\therefore \frac{d \sigma_{F}}{d x}=-\frac{2 \tau\left(x, r_{F}\right)}{r_{F}}
$$

In a similar manner, the equilibrium equations for the infinitesimal fiber coating and adhesive layer are represented, respectively, as follows:

$$
\begin{aligned}
& \therefore \frac{d \sigma_{C}}{d x}=-\frac{2\left[r_{F} \tau\left(x, r_{F}\right)-r_{C} \tau\left(x, r_{C}\right)\right]}{r_{C}^{2}-r_{F}^{2}} \\
& \therefore \frac{d \sigma_{A}}{d x}=-\frac{\pi r_{C} \tau\left(x, r_{C}\right)-W_{A} \tau(x, r)}{W_{A}\left(r_{C}+r\right)-\frac{1}{2} \pi r_{C}{ }^{2}}
\end{aligned}
$$

Equation (7) can be written as below.

$$
\tau(x, r)=\frac{1}{W_{A}}\left\{\pi r_{C} \tau\left(x, r_{C}\right)-\left[W_{A}\left(r_{C}+r\right)-\frac{1}{2} \pi r_{C}^{2}\right] \frac{d \sigma_{A}}{d x}\right\}
$$

From Equation (6),

$$
r_{C} \tau\left(x, r_{C}\right)=-\frac{1}{2} \pi\left(r_{C}^{2}-r_{F}^{2}\right) \frac{d \sigma_{C}}{d x}+r_{F} \tau\left(x, r_{F}\right)
$$


Equation (10) can be derived by substituting Equation (5) into Equation (9), as follows.

$$
\therefore \tau(x, r)=\frac{\pi r_{F}^{2}}{2 W_{A}} \frac{d \sigma_{F}}{d x}-\frac{\pi\left(r_{C}{ }^{2}-r_{F}^{2}\right)}{2 W_{A}} \frac{d \sigma_{C}}{d x}-\left(r_{C}+r-\frac{\pi r_{C}{ }^{2}}{2 W_{A}}\right) \frac{d \sigma_{A}}{d x}
$$

The stress transfer between the FRP and the OF is mostly dominated by the shear modulus of elasticity, followed by the radial deformation of the OF. Thus, the Poisson effect can be ignored. Equation (11) can be derived by substituting $\sigma=E \varepsilon, \varepsilon=d u / d x$ into Equation (10).

$$
\begin{aligned}
\therefore \tau(x, r) & =-\frac{\pi r_{F}^{2} E_{F}}{2 W_{A}} \frac{d \varepsilon_{F}}{d x}-\frac{\pi\left(r_{C}^{2}-r_{F}^{2}\right) E_{C}}{2 W_{A}} \frac{d \varepsilon_{C}}{d x}-\left(r_{C}+r-\frac{\pi r_{C}{ }^{2}}{2 W_{A}}\right) E_{A} \frac{d \varepsilon_{A}}{d x} \\
& =E_{F}\left[-\frac{\pi \cdot r_{F}^{2}}{2 W_{A}} \frac{d \varepsilon_{F}}{d x}-\frac{\pi\left(r_{C}^{2}-r_{F}^{2}\right)}{2 W_{A}} \frac{E_{C}}{E_{F}} \frac{d \varepsilon_{C}}{d x}-\left(r_{C}+r-\frac{\pi r_{C}{ }^{2}}{2 W_{A}}\right) \frac{E_{A}}{E_{F}} \frac{d \varepsilon_{A}}{d x}\right]
\end{aligned}
$$

The deformations of all layers are almost the same.

$$
\frac{d \varepsilon_{C}}{d x} \cong \frac{d \varepsilon_{A}}{d x} \cong \frac{d \varepsilon_{F}}{d x}
$$

Equation (13) can be obtained by substituting Equation (12) into Equation (11), as follows.

$$
\tau(x, r)=\left[-\frac{\pi r_{F}^{2}}{2 W_{A}} E_{F}-\frac{\pi\left(r_{C}^{2}-r_{F}^{2}\right)}{2 W_{A}} E_{C}-\left(r_{C}+r-\frac{\pi r_{C}^{2}}{2 W_{A}}\right) E_{A}\right] \frac{d \varepsilon_{F}}{d x}
$$

Since the FBG sensor exhibits a long aspect ratio, the radial displacement can be ignored. That is,

$$
\tau(x, r)=G_{A} \gamma(x, r)=G_{A} \gamma\left(\frac{\partial u}{\partial r}+\frac{\partial w}{\partial x}\right) \cong G_{A} \frac{\partial u}{\partial r}
$$

When Equation (14) is substituted into Equation (12) and then integrated with $\left(r_{F}, r_{H}\right)$,

$$
\begin{gathered}
\int_{r_{F}}^{r_{H}}\left(G_{A} \frac{d u}{d r}\right) d r=-\int_{r_{F}}^{r_{H}}\left[\frac{\pi r_{F}^{2}}{2 W_{A}} E_{F}+\frac{\pi\left(r_{C}^{2}-r_{F}^{2}\right)}{2 W_{A}} E_{C}+\left(r_{C}+r-\frac{\pi r_{C}^{2}}{2 W_{A}}\right) E_{A}\right] d r \\
u_{H}-u_{F}=-\frac{r_{H}-r_{F}}{W_{A}-G_{A}}\left\{\frac{\pi}{2} r_{F}^{2} E_{F}+\frac{\pi}{2}\left(r_{C}^{2}-r_{F}^{2}\right) E_{C}+\left[W_{A}\left(r_{C}+\frac{r_{F}}{2}+\frac{r_{H}}{2}\right)-\frac{\pi}{2} r_{C}^{2}\right] E_{A}\right\} \frac{d \varepsilon_{F}}{d x}=-\frac{1}{k^{2}} \frac{d \varepsilon_{F}}{d x}
\end{gathered}
$$

Thus, we can obtain;

$$
k=\sqrt{\frac{W_{A}-G_{A}}{\left(r_{H}-r_{F}\right)\left\{\frac{\pi}{2} r_{F}^{2} \cdot E_{F}+\frac{\pi}{2}\left(r_{C}^{2}-r_{F}^{2}\right) \cdot E_{C}+\left[W_{A}\left(r_{C}+\frac{r_{F}}{2}+\frac{r_{H}}{2}\right)-\frac{\pi}{2} r_{C}^{2}\right] \cdot E_{A}\right\}}}
$$

where $k$ is the strain lag parameter reflecting the effects of the fiber core, coating, and adhesive layer. Differentiating Equation (16) with respect to $x$, yields:

$$
\frac{d^{2} \varepsilon_{F}(x)}{d x^{2}}-k^{2} \varepsilon_{F}(x)=-k^{2} \varepsilon_{H}
$$

The general solution of Equation (18) is:

$$
\varepsilon_{F}(x)=C_{1} e^{k x}+C_{2} e^{-k x}+\varepsilon_{H}
$$

$C_{1}$ and $C_{2}$ are the integration constants and obtained by considering the boundary condition that the axial stress of the fiber core is assumed free at both ends. 


$$
\begin{gathered}
\varepsilon_{F}\left(L_{F}\right)=-\varepsilon_{F}\left(L_{F}\right)=0 \\
C_{1}=C_{2}=\frac{\varepsilon_{H}}{2 \cosh \left(K \cdot L_{F}\right)}
\end{gathered}
$$

Thus, the strain relationship of the fiber core to the host material at a given $x$ coordinate is

$$
\varepsilon_{F}(x)=\varepsilon_{H}\left(1-\frac{\cosh (K \cdot x)}{\cosh \left(K \cdot L_{F}\right)}\right)
$$

The maximum strain transfer rate $\psi_{H}(0)$ happens at the midpoint of the fiber core (i.e., the point where $x$ is equal to zero) and yields to:

$$
\psi_{H}(0)=\frac{\varepsilon_{F}(0)}{\varepsilon_{H}}=1-\frac{1}{\cosh \left(K \cdot L_{F}\right)}
$$

Average strain transfer rate $\psi_{\text {avg }}$ can be expressed as:

$$
\psi_{\text {avg }}=\frac{\overline{\varepsilon_{F}(x)}}{\varepsilon_{H}}=\frac{2 \int_{0}^{L} \varepsilon_{F}(x) d x}{2 L_{F} \cdot \varepsilon_{H}}=1-\frac{\sinh \left(K \cdot L_{F}\right)}{K L_{F} \cosh \left(K \cdot L_{F}\right)}
$$

\section{Evaluation of the Sensing Capacity of FRP Strip with Fiber Optic Sensor}

The transfer of strain between the OF and FRP of specimens shown in Table 6 was evaluated in accordance with the aforementioned strain transfer mechanism. The mechanical properties of the OF, epoxy, and FRP are summarized in Table 8. These values are the information provided by the manufacturer and the values used by the previous researchers [26,27]. In addition, the cross-sectional dimensions of each material are shown in Table 9.

Table 8. Mechanical properties for the OF, epoxy, and FRP considered in the model.

\begin{tabular}{ccc}
\hline Material & Properties & Value \\
\hline \multirow{2}{*}{ Fiber core } & Young's modulus, $E_{F}\left(P_{a}\right)$ & $7.2 \times 10^{10}$ \\
& Poisson's ratio, $\lambda_{F}$ & 0.17 \\
\hline \multirow{2}{*}{ Fiber coating } & Young's modulus, $E_{C}\left(P_{a}\right)$ & $2.55 \times 10^{6}$ \\
& Poisson's ratio, $\lambda_{C}$ & 0.48 \\
\hline \multirow{2}{*}{ Epoxy } & Young's modulus, $E_{A}\left(P_{a}\right)$ & $3.4 \times 10^{9}$ \\
& Poisson's ratio, $\lambda_{A}$ & 0.34 \\
& Shear modulus, $G_{A}\left(P_{a}\right)$ & $1.27 \times 10^{9}$ \\
\hline \multirow{2}{*}{ FRP } & Young's modulus, $E_{H}\left(P_{a}\right)$ & $1.65 \times 10^{8}$ \\
& Poisson's ratio, $\lambda_{H}$ & 0.35 \\
\hline
\end{tabular}

Table 9. Dimensions of the OF, epoxy, and FRP in the model.

\begin{tabular}{cc}
\hline Material & Value $(\mathbf{m m})$ \\
\hline Half diameter of fiber core, $r_{F}$ & 0.0625 \\
Half diameter of fiber coating, $r_{C}$ & 0.125 \\
Half-thickness of epoxy, $r_{H}$ & 1.3 \\
Bonded width of epoxy, $W_{A}$ & 30 \\
Thickness of FRP, $W_{H}$ & 1.2 \\
\hline
\end{tabular}

Figure 18 shows the strain transfer from the FRP to the OF sensor evaluated using the analysis model according to the adhesion length. The horizontal axis represents the distance from the center of the specimen and the vertical axis represents the average strain transfer ratio from the FRP to the 
optical fiber. If the values on the vertical axis are close to " 1 ", it means that the transfer rate is close to $100 \%$. The $\mathrm{OF}$ adhesion length $L_{F}$ is changed from $10 \mathrm{~mm}$ to $50 \mathrm{~mm}$, and the strain transfer rate and the strain ratio of the OF to FRP decrease rapidly from each adhesion length to the end portion. In addition, as the adhesion length increases, the region where the strain transfer rate is close to 1.0 gradually increases. In the figure, the shaded part is the region where the FBG is formed in the OF, and its length is $5 \mathrm{~mm}$ from the center of the specimen. When $L_{F}$ is $10 \mathrm{~mm}$, the transfer rate decreases rapidly, even within a sensing part of $5 \mathrm{~mm}$, and the strain ratio of the OF to FRP also drops sharply. Therefore, when $L_{F}$ is $10 \mathrm{~mm}$, the strain that occurs in the FRP is not sufficiently transferred to the OF due to the shear lag phenomenon. On the other hand, when $L_{F}$ is not less than $20 \mathrm{~mm}$, there is almost no change in the average strain transfer, and a decrease in the strain ratio of the OF to FRP rarely occurs within the sensing part. Table 10 shows the calculated length of the region with the perfect transfer of strain for each adhesion length. When the adhesion length is $17 \mathrm{~mm}$, the perfect transfer of strain is possible up to $5 \mathrm{~mm}$, where the grating is formed. Therefore, an adhesion length of not less than this length is required. In the test result shown in Figure 17, when the adhesion length is $10 \mathrm{~mm}$, there is a significant difference in strains between the electric gauge and the optical fiber. On the other hand, almost similar results between those are obtained when it is not less than $20 \mathrm{~mm}$. This confirms that the values calculated using the model are very close to the test results. Therefore, it is expected that the proposed model can be used to properly predict the strain transfer of FRP strips with a fiber optic sensor and can also be utilized when determining the optimum dimensions.

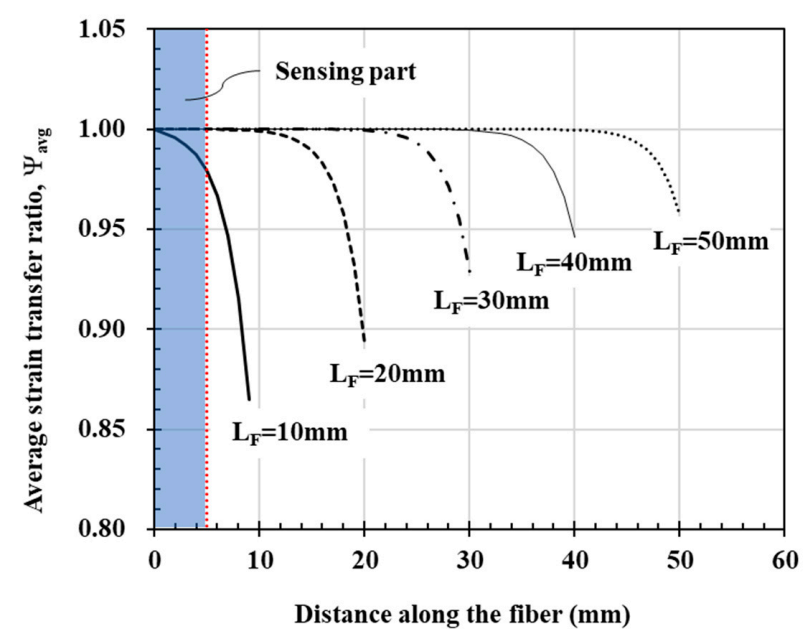

(a)

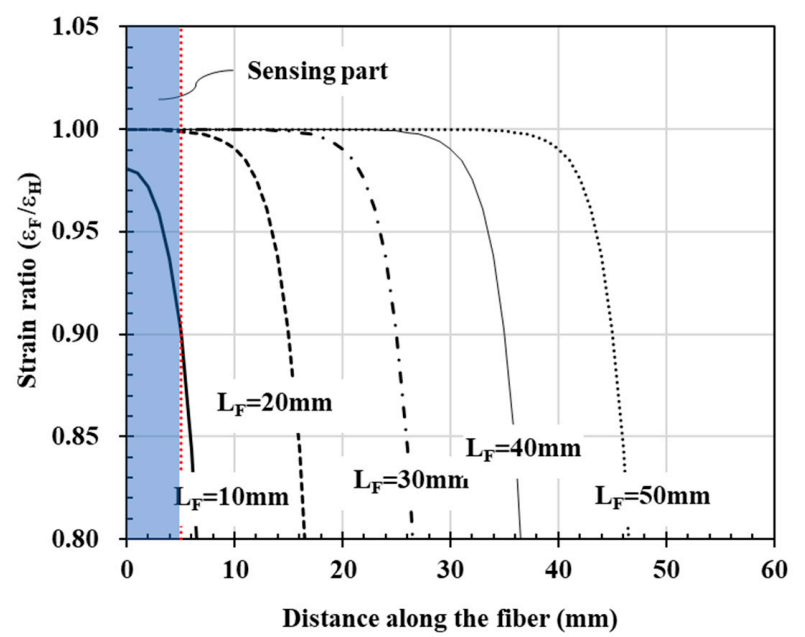

(b)

Figure 18. Evaluation of strain transfer from the FRP to the OF sensor: (a) Variation of the average transfer ratio, $\Psi_{\text {avg }} ;(\mathbf{b})$ Variation of the strain ratio, $\varepsilon_{F} / \varepsilon_{H}$. 
Table 10. Bond length of the OF with an FBG for effective sensing.

\begin{tabular}{cc}
\hline Bond Length, $\boldsymbol{L}_{\boldsymbol{F}} \mathbf{( \mathbf { m m } )}$ & $\begin{array}{c}\text { Possible Length for Perfect Transfer of } \\
\text { Strain from FRP to OF Sensor }(\mathbf{m m})\end{array}$ \\
\hline 10 & Impossible \\
17 & 5 \\
20 & 8 \\
30 & 18 \\
40 & 28 \\
50 & 38 \\
\hline
\end{tabular}

\section{Conclusions}

In this paper, an embedding method of a fiber optic sensor in the FRP was studied to develop FRP strip reinforcement with sensing capability for the retrofit of a reinforced concrete member in which the FRP is embedded into the concrete cover. To this end, a series of experiments were conducted to identify the tensile strength of the optical fiber in which an FBG is formed and examine the adhesive strength when attaching the optical fiber to the FRP with epoxy. In addition, an analysis model was applied to evaluate the sensing capacity according to the adhesion length when the FBG sensor was coupled to the FRP with epoxy and was then evaluated experimentally. The conclusions obtained through the study are as follows.

(1) As a result of the tensile test of the optical fiber with various adhesion length of optical fibers between two FRPs from 10 to $100 \mathrm{~mm}$, there was no difference in tensile strength up to $30 \mathrm{~mm}$ of adhesion length, but it tended to increase proportionally at a longer adhesion length. When the adhesion length was $100 \mathrm{~mm}$, the maximum strength was reached as the tensile fracture occurred in the optical fiber. At this time, the tensile strength obtained by dividing the load by the cross-sectional area including coating was $237 \mathrm{MPa}$ on average. When the FBG was formed in the optical fiber, the tensile strength decreased by about $21.6 \%$ due to laser-inflicted damage when compared to the case without FBG. In this case, the tensile strength of the optical fiber with the FBG formed was reached when the adhesion length of the optical fiber was not less than $10 \mathrm{~mm}$.

(2) When the optical fiber with the FBG was placed between two FRP strips and then integrated with epoxy resin to fabricate the FRP strip with a fiber optic sensor, and the adhesion length "L" of the optical fiber was changed from 10 to $50 \mathrm{~mm}$, the optical fiber sensor of the FRP strip with adhesion length " $\mathrm{L}$ " of $10 \mathrm{~mm}$ consistently showed the value corresponding to $74 \%$ of the strain of electric gauge. This is because the deformation that occurs in the FRP is not sufficiently transferred to the optical fiber due to the shear lag effect. On the other hand, when the adhesion length was not less than $20 \mathrm{~mm}$, the strain of the optical fiber sensor was found to be almost identical to that of the electric gauge. These results suggest that an adhesion length of $20 \mathrm{~mm}$ or more in one direction from the center, with a total adhesion length of more than $40 \mathrm{~mm}$, needs to be secured when the optical fiber is attached and fixed between the two FRP strips with epoxy.

(3) Based on the theoretical model of existing researchers, the model of the FRP strip with a fiber optic sensor in which the optical fiber is embedded into two FRP strips was built, and the sensing performance according to the adhesion length was evaluated. The results show that when the adhesion length is $10 \mathrm{~mm}$, there is a significant difference between the strain value of the electric gauge and the strain of the optical fiber. On the other hand, almost similar results in the two sensors are obtained when it is not less than $20 \mathrm{~mm}$. This confirms that the values calculated using the model are very close to the test results. Therefore, it is expected that the proposed model can be used to properly predict the strain transfer of the FRP strip with a fiber optic sensor and can also be utilized when determining optimum dimensions. 
Author Contributions: S.-Y.S. made substantial contributions to the conceptualization of the study, analysis of the result, and editing and revising the article; J.-H.P. performed the experiment and analyzed the result; H.-D.Y. analyzed the test result and reviewed the manuscript. K.-S.K. validated the result and reviewed the manuscript. All authors have read and agreed to the published version of the manuscript.

Funding: This research was supported by the Basic Science Research Program through the National Research Foundation of Korea (NRF) funded by the Ministry of Education (No. 2018R1A4A1025953).

Conflicts of Interest: The authors declare no conflict of interest.

\section{References}

1. Fernando, F.; Hameed, A.; Winter, D.; Tetlow, J.; Leng, J.; Barnes, R.; Mays, G.; Kister, G. Structural integrity monitoring of concrete structures via optical fibre sensors: Sensor protection systems. Struct. Health Monit. 2003, 2, 123-135. [CrossRef]

2. Zhang, W.; Gao, J.; Shi, B.; Cui, H.; Zhu, H. Health monitoring of rehabilitated concrete bridges using distributed optical fibre sensing. Comput. Aided Civ. Infrastruct. Eng. 2006, 21, 411-424. [CrossRef]

3. Moyo, P.; Brownjohn, M.; Suresh, R.; Tjin, C. Development of fibre Bragg grating sensors for monitoring civil infrastructure. Eng. Struct. 2005, 27, 1828-1834. [CrossRef]

4. Hill, K.O.; Fujii, Y.; Johnson, D.C.; Kawasaki, B.S. Photosensitivity in optical fiber wave guides: Application to reflection fiber fabrication. Appl. Phys. Lett. 1978, 32, 647. [CrossRef]

5. Merzbacher, I.; Kersey, D.; Friebele, J. Fibre optic sensors in concrete structures: A review. Smart Mater. Struct. 1996, 5, 196-208. [CrossRef]

6. Ansari, F. State-of-the-art in the applications of fibre-optic sensors to cementitious composites. Cem. Concr. Compos. 1997, 19, 3-19. [CrossRef]

7. Lopez-Higuera, J.M.; Cobo, L.R.; Inceral, A.Q.; Corbo, A. Fiber optic sensors in structural health monitoring. J. Lightwave Technol. 2011, 29, 587-608. [CrossRef]

8. Chung, W.; Kim, S.; Kim, N.; Lee, H. Deflection estimation of a full scale prestressed concrete girder using long-gauge fibre optic sensors. Constr. Build. Mater. 2008, 22, 394-401. [CrossRef]

9. Huang, S.; Ohn, M.M.; LeBlanc, M.; Measures, R.M. Continuous arbitrary strain profile measurements with fibre bragg grating. J. Smart Mater. Struct. 1998, 7, 248-256. [CrossRef]

10. Udd, E. Applications of Fiber Optic Smart Structures. In Proceedings of the IEEE Technical Applications Conference, Northcon/96, Conference Record, Seattle, WA, USA, 4-6 November 1996; Volume 96.

11. Lau, K.T.; Yuan, L.; Zhou, L.M.; Wu, J.; Woo, C.H. Strain monitoring in FRP laminates and concrete beams using FBG sensors. Comp. Struct. 2001, 51, 9-20. [CrossRef]

12. Zhao, Y.; Ansari, F. Embedded fiber optic sensor for characterization interface strains in FRP composite. Sens. Actuators A 2002, 100, 247-251. [CrossRef]

13. Oliveira, R.; Ramos, C.A.; Marques, A.T. Health monitoring of composite structures by embedded FBG and interferometric Fabry-Pérot sensors. Comput. Struct. 2008, 86, 340-346. [CrossRef]

14. Lau, K. Structural health monitoring for smart composites using embedded FBG sensor technology. Mater. Sci. Technol. 2014, 30, 1642-1654. [CrossRef]

15. Geng, X.; Jiang, M.; Gao, L.; Wang, Q.; Jia, Y.; Sui, Q.; Jia, L. Sensing characteristics of FBG sensor embedded in CFRP laminate. Measurement 2017, 98, 199-204. [CrossRef]

16. Chan, Y.W.S.; Zhou, Z. Advances of FRP-based smart components and structures. Pac. Sci. Rev. 2014, 16, 1-7. [CrossRef]

17. Wang, C.; Cheng, L. Use of fiber brag grating sensors for monitoring concrete structures with prestressed near-surface mounted carbon fiber- reinforcement polymer strips. J. Intell. Mater. Syst. Struct. 2014, 25, 164-173. [CrossRef]

18. Schaller, M.B.; Kaseberg, S.; Kuhne, M. Smart CFRP systems for the controlled retrofitting of reinforced concrete members. Proc. SPIE Int. Soc. Opt. Eng. 2010, 7653. [CrossRef]

19. Sundaram, B. Monitoring of FRP strengthened concrete structures using FBG sensors. Procedia Eng. 2011, 14, 1549-1556. [CrossRef]

20. Wang, B. Strain monitoring of RC members strengthened with smart NSM FRP bars. Constr. Build. Mater. 2009, 23, 1698-1711. [CrossRef] 
21. EI-Hacha, R.; Rizkalla, S. Near-Surface- Mounted Fiber-Reinforced Polymer Reinforcements for Flexural Strengthening of concrete Structures. ACI Struct. J. 2004, 101, 717-726.

22. Seo, S.; Feo, L.; Hui, D. Bond strength of near-surface-mounted FRP plate for retrofit of concrete structures. Compos. Struct. 2013, 95, 719-727. [CrossRef]

23. Sharaky, I.; Torres, L.; Comas, J.; Barris, C. Flexural Response of Reinforced Concrete (RC) Beams Strengthened with Near Surface Mounted (NSM) Fibre Reinforced Polymer (FRP) Bars. Compos. Struct. 2014, 109, 8-22. [CrossRef]

24. Seo, S.; Choi, K.; Kwon, Y.; Lee, K. Flexural Strength of RC Beam Strengthened by Partially De-bonded Near-Surface-Mounted FRP Strip. Int. J. Concr. Struct. Mater. 2016, 10, 149-161. [CrossRef]

25. Seo, S.; Lee, M.S.; Feo, L. Flexural analysis of RC beam strengthened by partially de-bonded NSM FRP strip. Compos. Part B 2016, 101, 21-30. [CrossRef]

26. Zhao, H.; Wang, Q.; Qiu, Y.; Chen, J.; Wang, Y.; Fan, Z. Strain transfer of Surface-bonded fiber Bragg grating sensors for airship envelope structural health monitoring. J. Zhejiang Univ. Sci. A Appl. Phys. Eng. 2012, 13, 538-545. [CrossRef]

27. Ansari, F.; Libo, Y. Mechanics of bond and interface shear transfer in optical fiber sensor. J. Eng. Mech. 1998, 124, 385-394. [CrossRef]

28. Benedetti, A.; Fernandes, P.; Granja, J.L.; Sena-Cruz, J.; Azenha, M. Influence of temperature on the curing of an epoxy adhesive and its influence on bond behaviour of NSM-CFRP systems. Compos. Part B Eng. 2016, 89, 219-229. [CrossRef]

29. ASTM D3039M-17. Standard Test Method for Tensile Properties of Polymer Matrix Composite Materials; ASTM Standard: West Conshohocken, PA, USA, 2017.

30. Werneck, M.M.; Allil, R.C.S.B.; Ribeiro, B.A.; Nazare, F.V.B. A guide to Fiber Bragg Grating Sensors; INTECH: Vienna, Austria, 2013. [CrossRef]

31. Song, I.C.; Lee, S.K.; Jeong, S.H.; Lee, B.H. Absolute strain measurements made with fiber bragg grating sensors. Appl. Opt. 2004, 43, 1337-1341. [CrossRef]

32. Pak, Y.E. Longitudinal shear transfer in fiber optic sensors. Smart Mater. Struct. 1992, 1, 6926-6941. [CrossRef]

33. Zhou, J.; Zhou, Z.; Zhang, D. Study on strain transfer characteristics of fiber Bragg grating sensors. J. Intell. Mater. Syst. Struct. 1992, 21, 1117-1122. [CrossRef]

Publisher's Note: MDPI stays neutral with regard to jurisdictional claims in published maps and institutional affiliations.

(C) 2020 by the authors. Licensee MDPI, Basel, Switzerland. This article is an open access article distributed under the terms and conditions of the Creative Commons Attribution (CC BY) license (http://creativecommons.org/licenses/by/4.0/). 